\title{
Colorectal Mucinous Adenocarcinoma
}

National Cancer Institute

\section{Source}

National Cancer Institute. Colorectal Mucinous Adenocarcinoma. NCI Thesaurus. Code C43585.

An invasive colorectal adenocarcinoma characterized by the presence of extracellular mucin pools that contain malignant glandular epithelial structures. The extracellular mucin pools occupy more than $50 \%$ of the malignant lesion. 